\title{
Characterization and biological functions of sulfated polysaccharides from sulfated-salt treatment of Antrodia cinnamomea
}

\author{
Jing-Jy Cheng ${ }^{a}$, Nai-Kuei Huang ${ }^{a}$, Huu-Sheng Lur ${ }^{b}$, Chung-Io Kuo ${ }^{b}$, Mei-Kuang Lu ${ }^{\text {a,* }}$ \\ ${ }^{a}$ National Research Institute of Chinese Medicine, Taipei, Taiwan \\ bepartment of Agronomy, National Taiwan University, Taipei, Taiwan
}

\section{A R T I C L E I N F O}

\section{Article history:}

Received 25 September 2008

Received in revised form 21 November 2008 Accepted 12 December 2008

\section{Keywords:}

Antrodia cinnamomea

Sulfated polysaccharides

Angiogenesis

Pheochromocytoma cells

Neuroprotection

Apoptosis

\begin{abstract}
A B S T R A C T
Sulfated polysaccharides (SPSs) of Antrodia cinnamomea were extracted by an exhaustive papain digestion and characterized, and their biological functions were evaluated. In this study, we demonstrated the existence of SPSs in the medicinal fungus, A. cinnamomea. Since no SPSs had previously been identified in any fungal organism, we attempted to characterize those from $A$. cinnamomea. SPSs from A. cinnamomea inhibited in vitro Matrigel tube formation, in an angiogenesis model, in a dose-dependent manner. Furthermore, using serum deprivation-induced apoptosis in neuronal-like PC12 cells as a stress model, the SPSs of $A$. cinnamomea were effective in preventing serumdeprived apoptosis. Compositional analysis revealed that myo-inositol, fucose, galactose, and glucose were the neutral sugars in SPSs of A. cinnamomea, and these SPSs had a high sulfate content. The sulfation degree paralleled their antiangiogenic and neuroprotective activities. In this work, we report novel data on the structure, antiangiogenic, and neuroprotective effects of these fungal SPSs.
\end{abstract}

(C) 2009 Elsevier Ltd. All rights reserved.

\section{Introduction}

Sulfated polysaccharides (SPSs) are found in the structural skeleton of invertebrate connective tissues [1-5]. The physiological function of SPSs is to support the skeletal structure. SPSs are considered to be an attractive class of compounds as drug candidates for anticancer therapies. There is now clear evidence that recognition of cell-surface heparan sulfate, a similar structure of SPS, is required for growth factor actions during angiogenic process [6,7]. Commercially available PI-88 is a mixture of highly sulfated, monophosphorylated mannose oligosaccharides, derived from the extracellular phosphomannan of the yeast Pichia holstii [8], with potential antiangiogenic activity. PI-88 is currently in phase III clinical trials in the US. It is worthwhile screening this class of compounds found in nature.

Antrodia cinnamomea, also known by its Chinese name, niuchang-chin, in Taiwan, is a medicinal fungus of the family Polyporaceae that grows slowly in the inner cavity of the camphor tree, Cinnamomum kanehirai [9]. It is an indigenous and rare species in Taiwan. It has recently been used in the formulation of neutraceuticals and functional foods due to many of its bioactive constituents being discovered, and are commercially available in

\footnotetext{
* Corresponding author at: National Research Institute of Chinese Medicine, 155 1 Li-Nung St., Sec. 2, Shipai, Peitou, Taipei 112, Taiwan, ROC. Tel.: +886 2 28201999x7391; fax: +886228264276.

E-mail address: mklu@nricm.edu.tw (M.-K. Lu).
}

Taiwan. A. cinnamomea has not only been utilized to treat a wide variety of diseases, but has also drawn the attention of the pharmaceutical industry. Traditionally, it has been used to treat intoxication caused by food, alcohol, and drugs as well as to treat diarrhea, abdominal pain, hypertension, itchy skin, and tumorigenic diseases [10]. Chemical compounds found in A. cinnamomea include sesquiterpene lactone, steroids, and triterpenoids [11-14]. Recently, differential extracts of $A$. cinnamomea have been shown to exert antioxidative [15-17], vasorelaxation [18], anti-inflammatory [19], and antihepatic effects [20]. Attemptes to obtain optimal submerged culture conditions for polysaccharide production in this species was reported [21].

Angiogenesis is a dynamic process of endothelial proliferation and differentiation. Cancer cells are able to produce large amounts of several angiogenic factors including basic-fibroblast-like growth factor (bFGF) and vascular endothelial growth factor (VEGF), interleukin 8 (IL-8), transforming growth factors- $ß$ (TGF- $ß$ ), and others that cause endothelial cell recruitment and proliferation [22]. Tumors with high angiogenic activity have been connected with aggressiveness and poor patient survival [23-25], and blocking the nutrient supply to cause a rapid and selective shutdown of new blood vessel and tumor growth is an effective cancer therapy. Fungal polysaccharopeptides (PSPs) from Coriolus versicolor are commercially available and have inhibitory effects on tumor angiogenesis and tumor growth in mice [26]. For the ease of commercial production of polysaccharides in submerged fermentation, it is worthwhile to investigate this class of compounds to develop a potential food supplement and for therapeutic uses. 
Recently, we showed that $A$. cinnamomea is effective in preventing serum-deprived PC12 cell apoptosis [27-29], suggesting a neuroprotective role. Neuronal death induced by apoptosis is a normal aspect of development in which it seems that the death program is triggered by the failure of a given neuron to receive limited supplies of target-derived neurotrophic factors. In the postdevelopmental period, neurons also undergo apoptotic death when deprived of appropriate trophic factors or are subjected to a variety of stresses and injuries. The rat PC12 cell line is a commonly used model for studies of neuronal differentiation and cell death. Apoptosis may occur when triggered by deprivation of either serum [30] or trophic factor/nerve growth factor (NGF) [31,32]. In this study, serum deprivation-induced PC12 cell death was used as an apoptotic model to investigate the mechanism of the extract of $A$. cinnamomea.

In a previous study, strain CCRC 35396 of $A$. cinnamomea grew fastest among all of the strains in our laboratory, and is rich in adenosine. It was also proven that adenosine can prevent cells from undergoing serum deprivation-induced apoptosis [28]. Therefore, in the present study, the antiangiogenic and antiapoptotic activity of SPSs from A. cinnamomea 35396 was evaluated as a reference for potential applications as health foods or drugs.

\section{Materials and methods}

\subsection{Reagents and cell culture}

All reagents were purchased from Sigma Chemical (St. Louis, MO, USA) except where otherwise specified. Dulbecco's modified Eagle's medium (DMEM), fetal bovine serum (FBS), and horse serum were purchased from HyClone (Logan, UT, USA). PC12 cells were maintained in DMEM supplemented with $10 \%(\mathrm{v} / \mathrm{v})$ horse serum and $5 \%(\mathrm{v} / \mathrm{v})$ FBS and incubated in a $\mathrm{CO}_{2}$ incubator $(5 \%)$ at $37^{\circ} \mathrm{C}$.

\subsection{Liquid culture of A. cinnamomed}

An A. cinnamomea isolate, strain 35396, was a generous gift from fungal specialist Dr. T.T. Chang (Division of Forest Protection, Taiwan Forest Research Institute, Taipei, Taiwan). Fungi were maintained on potato dextrose agar (PDA) slants and transferred to fresh medium at 3-week intervals. In each pasteurized Petri dish, $25 \mathrm{ml}$ of PDA medium $(39 \mathrm{~g} / \mathrm{l})$ was used. A fungus was inoculated at the center of a Petri dish which was then incubated at $28^{\circ} \mathrm{C}$ for 19 days. For liquid culture, 19-dayold seeding mycelium of $A$. cinnamomea was transferred to $100 \mathrm{ml}$ of $24 \mathrm{~g} / \mathrm{l}$ potato dextrose broth (PDB), and $20 \mathrm{~g} / \mathrm{l}$ glucose ( $\mathrm{pH}$ 5.6) with $\mathrm{MgSO}_{4}$ or $\mathrm{MnSO}_{4}$ in test concentrations of $0.05-0.50 \%$ for 49 days. At the end of the incubation, mycelia were rapidly washed with 11 of $250 \mathrm{mM} \mathrm{NaCl}$ using an aspirator-suction system to remove the contaminating culture medium. Samples were then lyophilized before use in the further experiments.

\subsection{Preparation of SPSs from A. cinnamomea}

SPSs were isolated according to Albano and Mourao [2] with the following modifications. Lyophilized mycelia $(1 \mathrm{~g})$ were extracted with $40 \mathrm{ml}$ of $0.1 \mathrm{M}$ sodium acetate (pH 5.5), containing $5 \mathrm{mM}$ cysteine, $100 \mathrm{mg}$ papain, and $5 \mathrm{mM}$ EDTA at $60^{\circ} \mathrm{C}$ for $24 \mathrm{~h}$. Supernatants were collected after centrifugation at $2000 \times g$ for $10 \mathrm{~min}$ at $4{ }^{\circ} \mathrm{C}$, and another $100 \mathrm{mg}$ papain in $40 \mathrm{ml}$ of the same buffer containing $5 \mathrm{mM}$ cysteine and $5 \mathrm{mM}$ EDTA was added to the precipitate for another $24 \mathrm{~h}$ at $60^{\circ} \mathrm{C}$. The supernatants of the two extractions were collected, and a 3.75 -fold volume of $95 \%$ ethanol was added, precipitated at $4{ }^{\circ} \mathrm{C}$ overnight, and spun at $9000 \times \mathrm{g}$ for $10 \mathrm{~min}$ at $4{ }^{\circ} \mathrm{C}$, and the pellets were collected. The pellets were dried and resuspended in $20 \mathrm{ml}$ of distilled water, dialyzed (MW 12,000-14,000 Da) against distilled water overnight at $4{ }^{\circ} \mathrm{C}$, and centrifuged at $9000 \times \mathrm{g}$ for $10 \mathrm{~min}$, then the supernatant was collected and lyophilized before use.

\subsection{Preparation of polysaccharides (PS) from A. cinnamomea}

Polysaccharides (denoted non-sulfated PS) extracted from the same species under same culture medium without the addition of $\mathrm{MgSO}_{4}$ or $\mathrm{MnSO}_{4}$ were used as negative control. The non-sulfated PS were isolated from lyophilized mycelia by hot water at $80^{\circ} \mathrm{C}$ in a $1: 100(\mathrm{w} / \mathrm{w})$ ratio for $6 \mathrm{~h}$ twice and cooled, and then four volumes of $95 \%$ ethanol were added and precipitated overnight at $4{ }^{\circ} \mathrm{C}$. The precipitated polysaccharides were collected by spinning at $9000 \times g$ for $20 \mathrm{~min}$ and lyophilized, resulting in a crude polysaccharide sample.

\subsection{Cell viability assay}

Survival was assessed by the 3-(4,5-dimethylthiazol-2-yl)-2,5-diphenyl tetrazolium bromide (MTT) assay as described by Mosmann [33]. Cells growing on 150- mm plates were washed three times with PBS and resuspended in DMEM. Suspended cells were plated on 96-well plates and treated with the indicated reagent(s) $\left(1 \times 10^{4}\right.$ cells/200 $\mu \mathrm{l} /$ well $)$. After incubation for $24 \mathrm{~h}, 20 \mu \mathrm{l}$ of MTT stock $\left(5 \mathrm{mg} / \mathrm{ml}\right.$ ) was added to the medium and incubated at $37^{\circ} \mathrm{C}$ for $3 \mathrm{~h}$. After discarding the medium, DMSO $(100 \mu \mathrm{l})$ was applied to the well to dissolve the formazan crystals derived from the mitochondrial cleavage of the tetrazolium ring by live cells. The absorbance at $570 / 630 \mathrm{~nm}$, which is highly correlated with the number of cells in each well was measured on a micro-ELISA reader. Cell viability was expressed as a percentage of the results of the MTT metabolism assay (o.d. 570/ $630 \mathrm{~nm}$ ) measured in the serum-containing group.

\subsection{Matrigel endothelial cell (EC) tube formation assays}

An EC tube formation assay was modified from a previously described method [34] Matrigel $(12.5 \mathrm{mg} / \mathrm{ml})$ was thawed at $4{ }^{\circ} \mathrm{C}$, and $50 \mu \mathrm{l}$ was quickly added to each well of a 96-well plate and allowed to solidify for $10 \mathrm{~min}$ at $37^{\circ} \mathrm{C}$. Once the gel had solidified, the wells were incubated for 30 min with ECs (30,000 cells/well). After adhesion of the cells, the medium was removed and replaced by fresh medium supplemented with VEGF with or without SPSs and incubated at $37^{\circ} \mathrm{C}$ for $24 \mathrm{~h}$. The growing tubes were visualized with an inverted Zeiss microscope (Germany) at a magnification of $10 \times$.

\subsection{Size-exclusion chromatography (SEC) of polysaccharides}

An SPS solution in milli-Q water was diluted to give a concentration of $1 \mathrm{mg} / \mathrm{ml}$ and was then filtered through a $0.22-\mu \mathrm{m}$ filter (Millipore, Bedford, MA) before injection into the SEC column. The flow rate was $0.5 \mathrm{ml} / \mathrm{min}$, with deionized water as the eluent. A calibration curve was constructed using an authentic standard, Sodex P-82 series (Showa Denko America, Mentor, $\mathrm{OH}$ ) containing polymaltotriose with molecular weights of $78.8 \times 10^{4}, 40.4 \times 10^{4}, 21.2 \times 10^{4}, 4.73 \times 10^{4}$, and $1.18 \times 10^{4} \mathrm{Da}$. The TriSec software program was used to acquire and analyze the Viscotek data. SEC signals were detected using a ViscoTek model TDA-3-1 relative viscometer (Viscotek, Houston, TX).

\subsection{Hydrolysis of SPSs}

Acid hydrolysis of the SPSs was carried out as follows. One milligram of lyophilized SPSs was hydrolyzed with $4.95 \mathrm{~N}$ trifluoroacetic acid (TFA) at $80^{\circ} \mathrm{C}$ in a heating block for $4 \mathrm{~h}$. The mixture was cooled and evaporated to remove the acid and then resuspended in milli- $\mathrm{Q}$ water.

\subsection{High-performance anion-exchange chromatographic (HPAEC) analysis of the carbohydrate composition of the SPSS}

After acid hydrolysis, the SPSs were separated on an HPAEC system (Dionex BioLC, Sunnyvale, CA) equipped with a gradient pump, a pulsed amperometric detector (PAD-II) using a gold working electrode, and an anion-exchange column (Carbopac PA-10, $4.6 \mathrm{~mm} \times 250 \mathrm{~mm}$, Dionex, Sunnyvale, CA). Samples were applied using an autosampler (AS3500, SpectraSYSTEM, Thermo Separation Products Inc., Riviera Beach, FL) via a microinjection valve with a $200-\mu l$ sample loop. The monosaccharides were analyzed at an isocratic $\mathrm{NaOH}$ concentration of $18 \mathrm{mM}$ at ambient temperature. Identification and quantification of the monosaccharides were made in comparison with standards. Data were collected and integrated on a PeakNet system (Dionex, Sunnyvale, CA).

\subsection{Determination of sulfate ion $\left(\mathrm{SO}_{4}{ }^{2-}\right)$}

The method for estimating the liberated sulfate ions was based on Saito et al. [35] with the following modifications. An aliquot $(300 \mu \mathrm{l})$ of the acid hydrolysis of SPS was pipetted into $700 \mu \mathrm{l}$ of the $\mathrm{BaCl}_{2}$-gelatin solution (see below). After mixing, the entire solution was allowed to stand for $10 \mathrm{~min}$ at room temperature. The absorbance of the test solution was measured against a blank at $360 \mathrm{~nm} . \mathrm{A} \mathrm{BaCl}_{2-}$ gelatin solution was prepared by dissolving $0.5 \mathrm{~g}$ gelatin in $100 \mathrm{ml}$ of distilled water at $60{ }^{\circ} \mathrm{C}$ and allowing it to stand at $4{ }^{\circ} \mathrm{C}$ overnight. To this solution, $1.48 \mathrm{ml}$ of $12.1 \mathrm{~N}$ $\mathrm{HCl}$ and $0.5 \mathrm{~g} \mathrm{BaCl}_{2}$ were added.

\subsection{Statistical analysis}

Statistical analysis was performed using Student's $t$-test. Data are presented as the mean \pm S.E.M. Statistical significance was defined as $p<0.05$.

\section{Results}

\subsection{Time-course study of growth}

To maximize production of the fungus, a time-course study was performed on the dry mass accumulation. In the culture period between 7 and 14 days, a linear phase of growth was observed. Beyond 21 days, the culture entered a senescent phase (Fig. 1). 


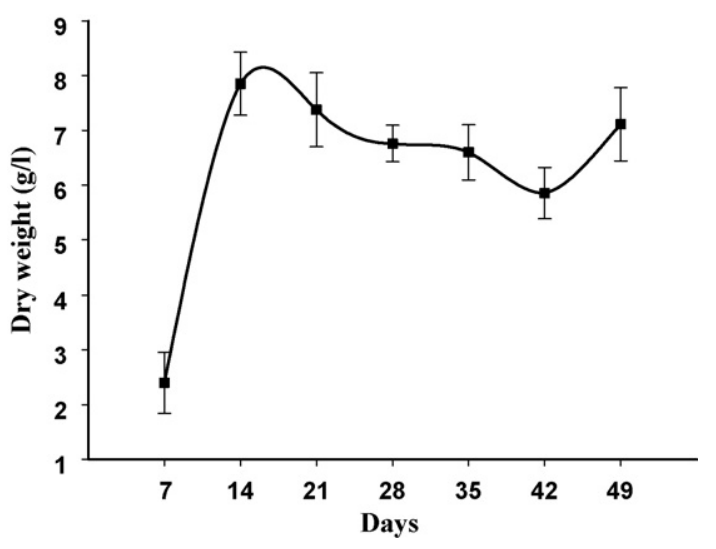

Fig. 1. Time course of the growth of A. cinnamomea. Data are presented as the mean \pm S.E. from three independent experiments.

3.2. Influence of $\mathrm{MgSO}_{4}$ and $\mathrm{MnSO}_{4}$ on mycelial growth and SPS production

To evaluate the effects of $\mathrm{MgSO}_{4}$ or $\mathrm{MnSO}_{4}$ on mycelial growth and SPS production, the dry biomass and yield of SPSs were measured (Fig. 2). Comparisons were made between control and $\mathrm{MgSO}_{4}$ - and $\mathrm{MnSO}_{4}$-treated cultures in the dose range of $0.05-0.5 \%$ of 49-day-cultured mycelia of $A$. cinnamomea. All $\mathrm{MgSO}_{4}$ treatments showed significantly enhanced mycelial growth compared to the control, whereas $\mathrm{MnSO}_{4}$ treatment inhibited mycelial
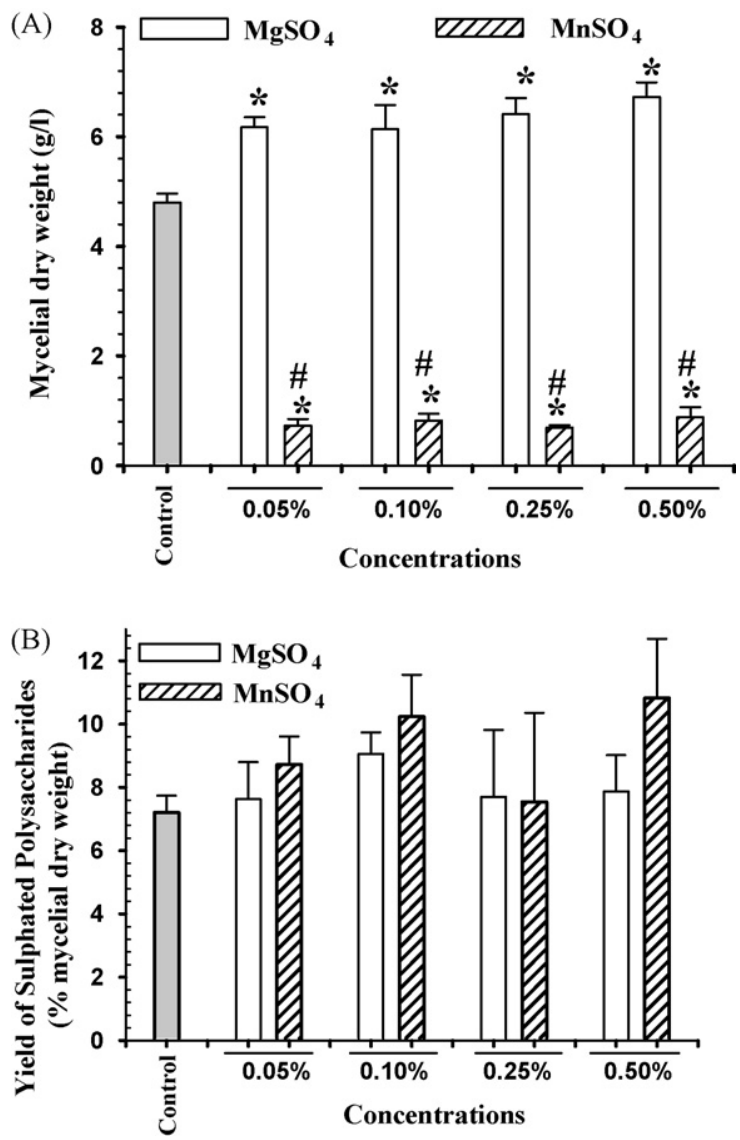

Fig. 2. Effect of $\mathrm{MgSO}_{4}$ and $\mathrm{MnSO}_{4}$ on the (A) dry weight; (B) yield of sulfated polysaccharides (SPSs) for 49 day-cultured $A$. cinnamomea. Data are presented as the mean \pm S.D. $(n=5)$. ${ }^{*} p<0.05$, compared with control by $t$-test. ${ }^{*} p<0.05$ vs. the control, ${ }^{\#} p<0.05$ vs. $\mathrm{MgSO}_{4}$. growth. All $\mathrm{MgSO}_{4}$ treatments showed higher levels of dry mass accumulation than those with $\mathrm{MnSO}_{4}$ treatment (Fig. $2 \mathrm{~A}$ ). $\mathrm{MgSO}_{4}-$ and $\mathrm{MnSO}_{4}$-treated mycelia exhibited no differences in SPS production (Fig. 2B).

\subsection{Effects of SPSs from A. cinnamomea on EC tube formation}

To study the effects of SPSs from A. cinnamomea on angiogenesis, an in vitro assay was performed to evaluate EC tube formation in Matrigel. Serial dilutions of SPSs from A. cinnamomea were evaluated for their effects on VEGF-induced angiogenesis revealed by tube formation on Matrigel (Fig. 3). SPSs from $\mathrm{MnSO}_{4}$-treated $A$. cinnamomea showed stronger inhibition of tube formation than did $\mathrm{MgSO}_{4}$-treated A. cinnamomea. SPSs of both $\mathrm{MgSO}_{4^{-}}$and $\mathrm{MnSO}_{4^{-}}$ treated A. cinnamomea showed dose-dependent inhibition of tube

(A)

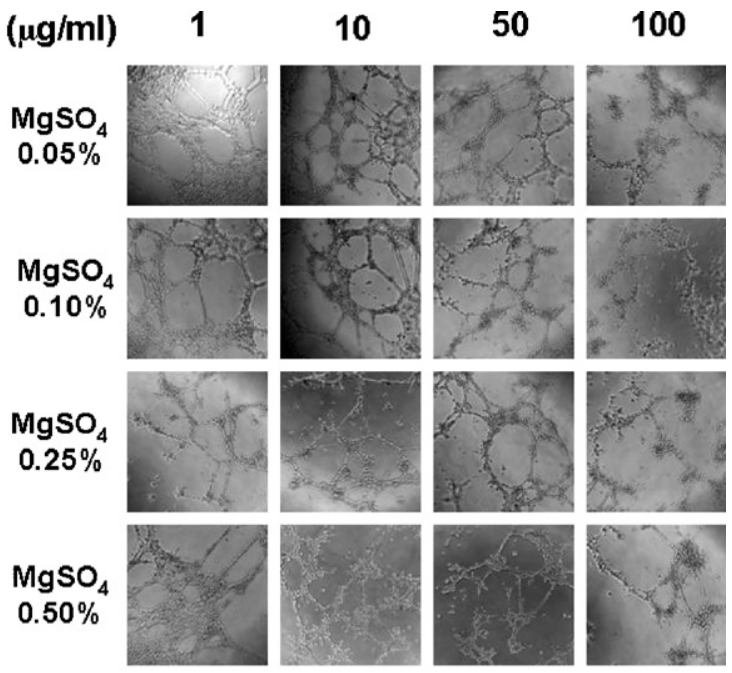

(B)
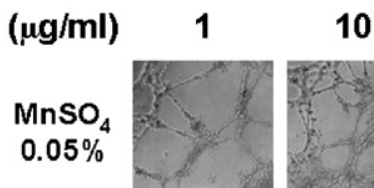

50

100
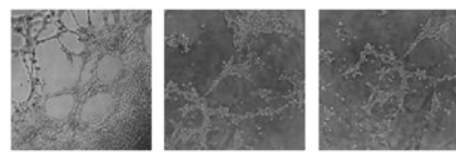

$\mathrm{MnSO}_{4}$ $0.10 \%$
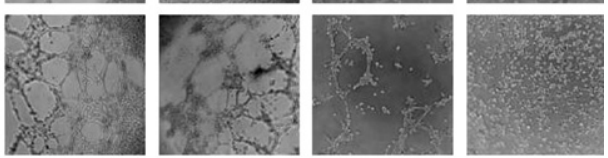

$\mathrm{MnSO}_{4}$ $0.25 \%$
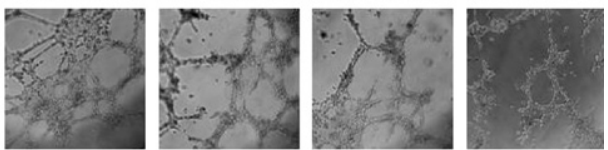

$\mathrm{MnSO}_{4}$ $0.50 \%$
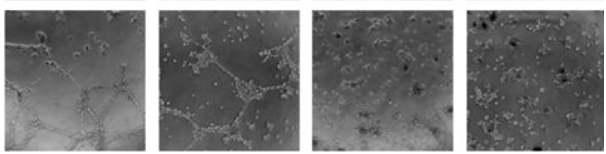

\section{Non-sulphated \\ PS}
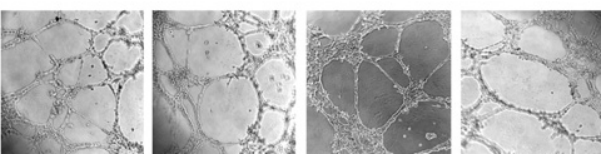

Fig. 3. Influences of sulfated polysaccharides (SPSs) of A. cinnamomea on endothelial cell (EC) tube formation. ECs were seeded onto Matrigel and cultured for $24 \mathrm{~h}$ with vascular endothelial growth factor (VEGF) with or without pretreatment with serial concentrations of SPSs from A. cinnamomea. Capillary tube formation on Matrigel was visualized with an inverted Zeiss microscope at a magnification of $10 \times$. Nonsulfated PS was used as a negative control. 
formation. The effect of non-sulfated polysaccharide (PS) on matrigel formation was almost not affected up to $100 \mu \mathrm{M}$ concentration. This assay revealed that EC tube formation was attenuated by treatment with SPSs from A. cinnamomea for $24 \mathrm{~h}$ (Fig. 3).

\subsection{Effects of SPSs from A. cinnamomea on serum deprivation- induced PC12 cell apoptosis}

SPSs from different concentrations of $\mathrm{MnSO}_{4}$-treated $\mathrm{A}$. cinnamomea were used to treat serum-deprived PC12 cells, and we found that only $0.5 \% \mathrm{MnSO}_{4}$ of SPSs dose-dependently prevented PC12 cells from serum deprivation-induced apoptosis (Fig. 4B). However, SPSs from $\mathrm{MgSO}_{4}$ treatment showed no protective effects (Fig. 4A).

\subsection{Effects of $\mathrm{MgSO}_{4}$ and $\mathrm{MnSO}_{4}$ on the molecular weight distribution and chemical composition of SPSs from A. cinnamomea}

To elucidate the effects of $\mathrm{MgSO}_{4}$ and $\mathrm{MnSO}_{4}$ on the structure of SPSs, SPSs were characterized according to their molecular weight distributions. The left panel of Fig. 5 shows results of $\mathrm{MgSO}_{4}$ treatment, and the right panel shows results of $\mathrm{MnSO}_{4}$ treatment. The molecular weight distributions of the SPS preparations were characterized as very high molecular weight ( $>5000 \mathrm{kDa}$, peak A), high molecular weight ( $>1000 \mathrm{kDa}$, peak $\mathrm{B})$, medium high
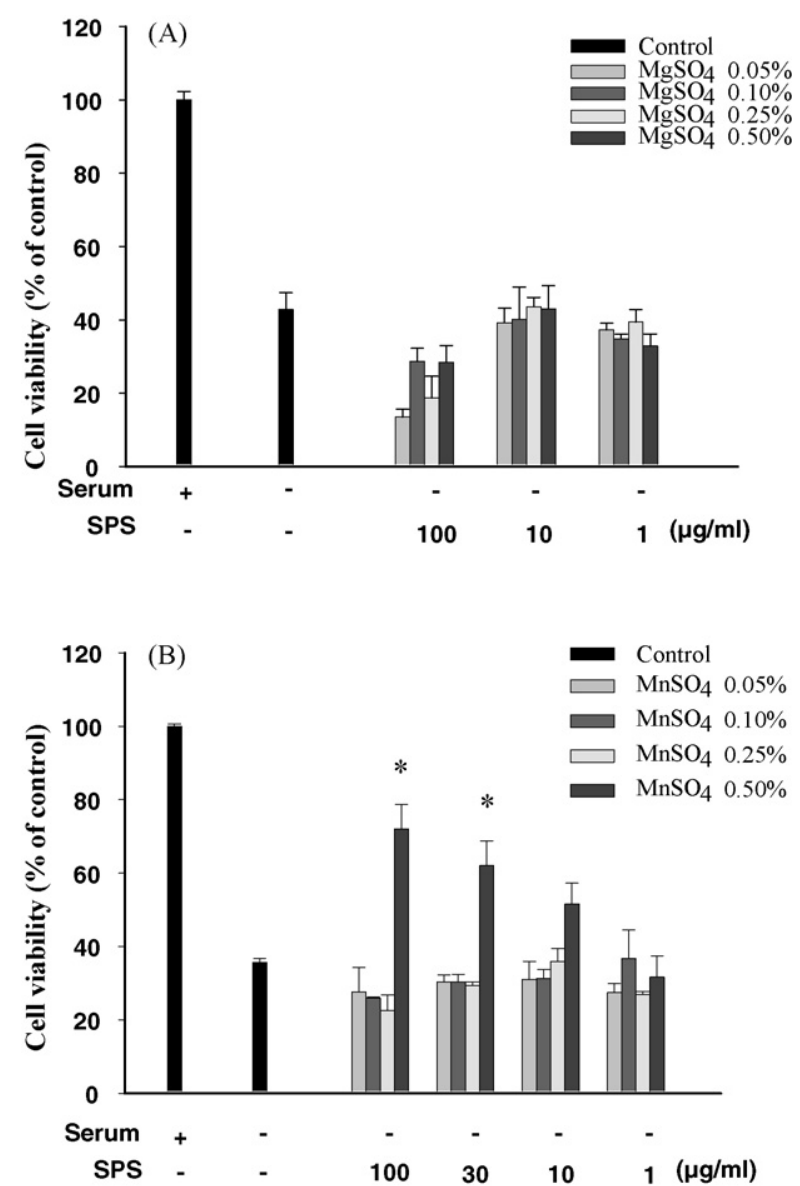

Fig. 4. Effect of $\mathrm{MgSO}_{4}$ and $\mathrm{MnSO}_{4}$ treatment on sulfated polysaccharides (SPSs) from A. cinnamomea on serum deprivation-induced PC12 cell apoptosis. Serumdeprived PC12 cells were treated with or without different concentrations of (A) $\mathrm{MgSO}_{4}$-treated and (B) $\mathrm{MnSO}_{4}$-treated SPSs for $24 \mathrm{~h}$. Cell viability was expressed as a percentage of the results of the MTT assay measured in the serum-contained control group. Data points represent the mean \pm S.E.M. of at least three independent experiments $(n=3-6) .{ }^{*} p<0.05$ compared to the serum-deprived group. molecular weight ( $>100 \mathrm{kDa}$, peaks $\mathrm{C}-\mathrm{E}$ ), and low molecular weight $(<100 \mathrm{kDa}$, peaks $\mathrm{F}$ and $\mathrm{G})$. The results showed that the synthesis of very-high-molecular weight SPSs of peak A increased when treated with $\mathrm{MgSO}_{4}$ at concentrations exceeding $0.1 \%$, and that of high-molecular-weight SPSs of peak B decreased. With $\mathrm{MgSO}_{4}$ treatment at concentrations of $0.05 \%, 0.1 \%$, and $0.25 \%$, the sums of the percent area of the medium-high-molecular-weight SPSs of peaks C, D, and E had values of $31.98 \%, 29.49 \%$, and $30.06 \%$, respectively. Almost no difference in all the tested concentrations of $\mathrm{MgSO}_{4}$ was shown for this molecular size range. Molecules of $<100 \mathrm{kDa}$ (peaks $\mathrm{F}$ and $\mathrm{G}$ ) in size accounted for half of the SPS population. With $\mathrm{MnSO}_{4}$ treatment at concentrations of $0.1 \%$, $0.25 \%$, and $0.5 \%$, the sums of the percent area showed that the medium-high-molecular-weight SPS peaks C, D, and E decreased to values of $36.77 \%, 34.03 \%$, and $27.96 \%$, respectively. With $0.5 \%$ $\mathrm{MnSO}_{4}$ treatment, a new species of SPS was synthesized with an Mn value of $90.74 \mathrm{kDa}$ (peak F); this SPS population was not present with the other $\mathrm{MnSO}_{4}$ treatments, and the low-molecularweight peak $\mathrm{G}$ with an $\mathrm{Mn}$ value of $6.69 \mathrm{kDa}$ represented the major population of SPSs. In contrast, the molecular weight distribution of non-sulfated PS was different from all the SPSs in that the molecular weight in the rang of 50-300 kDa was absent.

The chemical compositions of the SPSs were determined after each SPS was completely hydrolyzed (Table 1 ). The results showed that myo-inositol, galactose, and glucose were the predominant sugars in SPSs of $A$. camphorata. The sulfate content increased with an increasing concentration of both $\mathrm{MgSO}_{4}$ and $\mathrm{MnSO}_{4}$. In contrast, the sugar composition of non-sulfated PS was different from all the SPSs in that the concentration of fucose, galctose and glucose were higher than all the SPSs and sulfate was absent. To elucidate the most potent components in terms of antiangiogenic and neuroprotective activities, comparisons were made between the effective compounds treated with $\mathrm{MnSO}_{4}$, and the non-effective ones treated with $\mathrm{MgSO}_{4}$ in all the corresponding dosages. Sulfate may play important roles for the activity.

\section{Discussion}

To our knowledge, this is the first attempt to purify SPSs from a fungal species, A. cinnamomea. In this report, we used the CCRC35396 strain of A. cinnamomea and discuss dissimilarities in chemical and biological features between fungal and invertebrate SPSs. For our study to be successful, the physiological nature and chemical architecture of the bioactive domains of the SPSs had to be determined. Herein, a sulfated salt $\left(\mathrm{SO}_{4}{ }^{2-}\right)$ was used to stress the mycelial culture to derive our data.

In this study, there were significant qualitative changes in the sugar compositions, and degree of sulfation (Table 1) between $\mathrm{MgSO}_{4}$ and $\mathrm{MnSO}_{4}$ treatments of $A$. cinnamomea. It might have resulted in different biological functions. Our results indicated the same carbohydrate pattern as in the sea cucumber. Fucose was the major sugar species in SPSs of the sea cucumber [36]. Our results indicated that SPSs from A. cinnamomea contained common sugars (fucose, galactosamine, glucose, and galactose) which are also found in many invertebrate SPSs [2,37]. Nevertheless, the SPSs from $A$. cinnamomea differed from those of other species due to their relatively less-complex composition, as they mainly contained galactose and glucose (Table 1). Our findings indicated that SPSs from $0.5 \% \mathrm{MnSO}_{4}$-treated mycelia showed the most potent antiangiogenic (Fig. 3) and antiapoptotic activities (Fig. 4) However, non-sulfated PS did not exhibited angiogenic activity under the same concentration. The degree of sulfation of the SPSs increased as the dose of $\mathrm{MnSO}_{4}$ increased. The sulfate content of SPSs from $0.5 \% \mathrm{MnSO}_{4}$-treated mycelia was the highest among all treatments. This suggests that the degree of sulfation affected the antiangiogenic and neuroprotective properties. These results are 

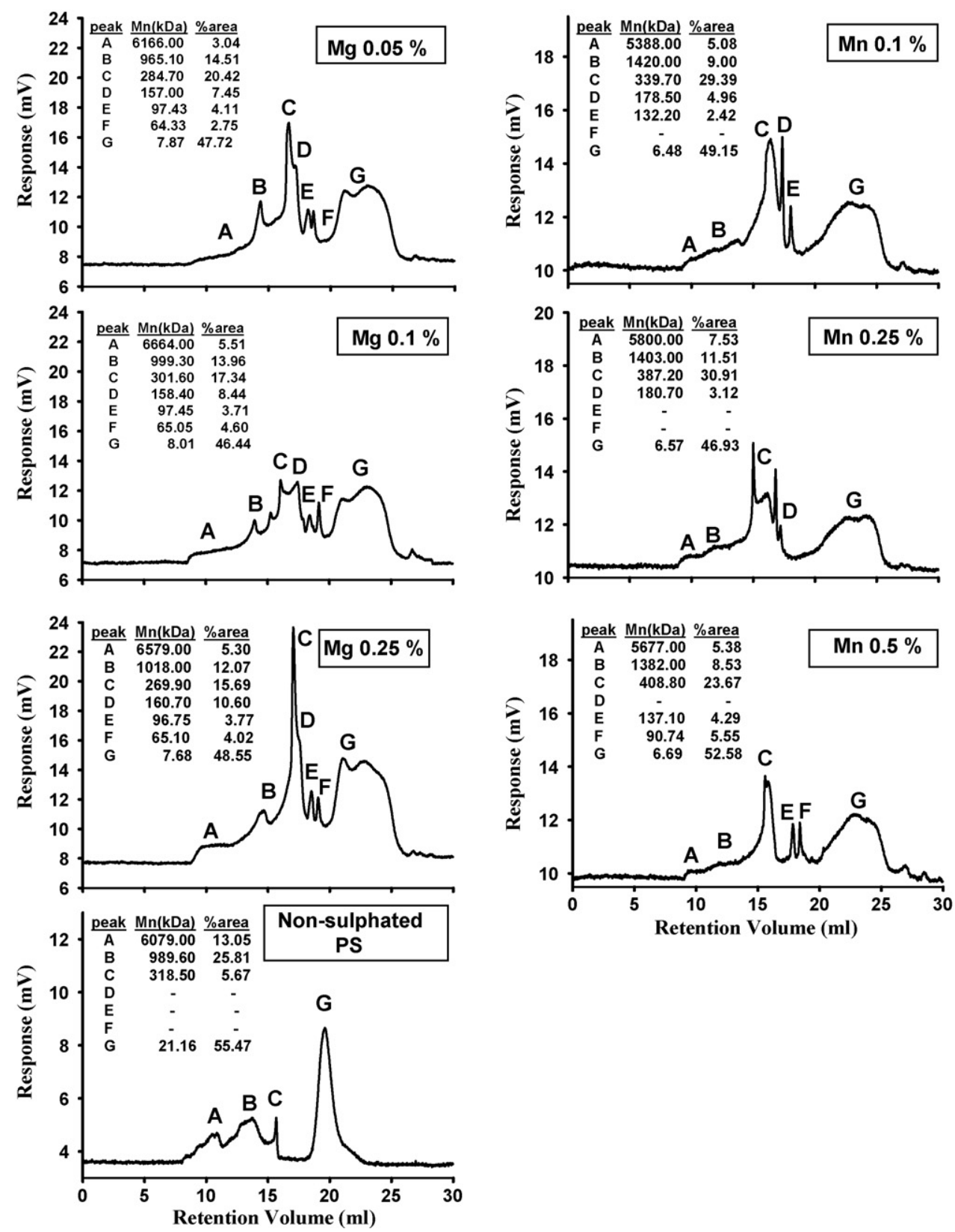

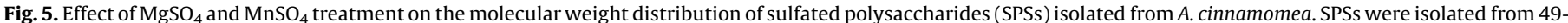

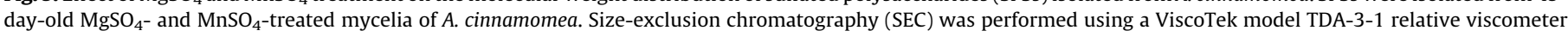

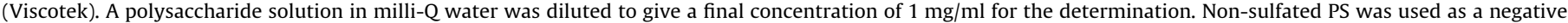
control.

consistent with those of Parish et al. [8] who found that the inhibitory activity against human angiogenesis of SPSs was critically dependent on the chain length and degree of sulfation. Highly sulfated linear oligosaccharides of five or more monosaccharides in length showed the greatest activity.

Characterization of the molecular weight distribution of these SPSs showed that a new species was synthesized with an Mn value of $90.74 \mathrm{kDa}$, and the low-molecular-weight peak G with an Mn value of $6.69 \mathrm{kDa}$ represented the major population of SPSs from $0.5 \% \mathrm{MnSO}_{4}$-treated mycelia (Fig. 5). These findings are in accord with the results of a previous study of synthetic sulfated oligosaccharides, which block heparan sulfate recognition by growth factors and inhibit cleavage of heparan sulfate by heparanase. Low-molecular-weight mimics of heparan sulfate showed the greatest effectiveness because it is now believed that cell surface heparan sulfates aid dimerization of growth factor receptors by growth factors [7].

Polysaccharides are getting increasing attention for therapeutic use in recent years. After extensive clinical trials, polysaccharopeptide Krestin (PSK) was approved for use in Japan in 1977, and polysaccharopeptide (PSP) appeared on the market about 10 years later [38]. In addition to fungal polysaccharides, low-molecularweight sulfated Escherichia coli K5 polysaccharide exerts antiangiogenic activity as a fibroblast growth factor (FGF) antagonist [39]. The K5 polysaccharide has the same structure as the heparin precursor. Heparin sulfate proteoglycans (HSPGs) modulate the binding of VEGF and FGFs with their respective receptors. HSPGs also stabilize the FGF-2/FGF receptor complex and VEGF/VEGF receptor complex. Regardless of the polysaccharide structure or sulfation degree, both contribute to the antiangiogenic activity. Angiogenic inhibitors may 
Table 1

Compositional analysis of the SPS from cultured mycelia of A. cinnamomea.

\begin{tabular}{|c|c|c|c|c|c|c|}
\hline \multirow[t]{2}{*}{ Treatment } & \multicolumn{6}{|l|}{ SPS $(\mu \mathrm{mol} / \mathrm{g})$} \\
\hline & Inositol & Fucose & Galactosamine & Galactose & Glucose & Sulfate ${ }^{a}$ \\
\hline Control & $27.70 \pm 5.86$ & $18.08 \pm 0.40$ & $1.00 \pm 0.48$ & $40.02 \pm 2.35$ & $26.21 \pm 1.54$ & $301.78 \pm 0.89$ \\
\hline $\mathrm{MgSO}_{4}$ 0.05\% & $15.88 \pm 3.69$ & $15.81 \pm 0.49$ & $15.72 \pm 2.92$ & $29.10 \pm 0.90$ & $61.22 \pm 5.31$ & $382.89 \pm 2.44$ \\
\hline $\mathrm{MgSO}_{4}$ 0.10\% & $17.05 \pm 6.33$ & $9.49 \pm 0.35$ & - & $46.46 \pm 8.34$ & $47.19 \pm 5.32$ & $382.22 \pm 0.89$ \\
\hline $\mathrm{MgSO}_{4}$ 0.25\% & $15.48 \pm 9.43$ & $23.93 \pm 13.48$ & - & $13.24 \pm 3.14$ & $24.29 \pm 1.31$ & $401.11 \pm 1.74$ \\
\hline $\mathrm{MgSO}_{4}$ 0.50\% & $8.09 \pm 0.03$ & $3.91 \pm 0.03$ & $1.03 \pm 0.03$ & $7.00 \pm 0.03$ & $28.44 \pm 0.10$ & $426.50 \pm 0.67$ \\
\hline $\mathrm{MnSO}_{4} 0.05 \%$ & $16.61 \pm 5.97$ & $6.00 \pm 4.13$ & $4.23 \pm 1.05$ & $106.36 \pm 7.31$ & $43.41 \pm 2.89$ & $701.11 \pm 2.07$ \\
\hline $\mathrm{MnSO}_{4} 0.10 \%$ & $12.65 \pm 0.33$ & $2.82 \pm 0.10$ & $7.44 \pm 0.62$ & $127.51 \pm 4.33$ & $21.08 \pm 0.87$ & $964.00 \pm 1.39$ \\
\hline $\mathrm{MnSO}_{4} 0.25 \%$ & $15.67 \pm 3.93$ & $5.48 \pm 1.41$ & $7.64 \pm 0.88$ & $112.45 \pm 8.06$ & $39.14 \pm 2.48$ & $1044.66 \pm 3.63$ \\
\hline $\mathrm{MnSO}_{4} 0.50 \%$ & $10.11 \pm 4.94$ & $3.10 \pm 0.39$ & $10.12 \pm 0.92$ & $114.53 \pm 0.05$ & $25.12 \pm 0.73$ & $1075.11 \pm 5.39$ \\
\hline Non-sulfated PS & $18.47 \pm 0.93$ & $115.78 \pm 1.43$ & - & $408.71 \pm 7.67$ & $101.57 \pm 2.57$ & - \\
\hline
\end{tabular}

a Sulfate was determined by the $\mathrm{BaCl}_{2}$-gelatin method [35].

possibly interfere with FGF-2 or VEGF activity in two ways: either directly by blocking the interaction of VEGF or FGF with their receptors or by disrupting the bystander effect of HSPGs for efficient growth factor binding. Therefore, in this study, the possible mechanism of angiogenesis inhibition or neuroprotective activity of SPSs from A. cinnamomea might have been due to the similar structural characteristics to sulfated proteoglycans.

In conclusion, this investigation of the existence of antiangiogenic and neuroprotective effects of fungal SPSs is truly novel and presents important findings. We identified that SPSs simultaneously inhibited angiogenesis by inhibition of EC tube formation and neuroprotective activities. However, the physiological significance of fungal SPSs is not completely understood. Do compositional differences in the sugars, sulfation degree, or polysaccharide structure cause the different biological functions between invertebrate and fungal SPSs? This study describes the successful use of an in vitro approach to study fungal SPSs as drug candidates. Further study should be performed to validate the specific active components.

\section{Acknowledgements}

We thank Dr. Tun-Tschu Chang, Division of Forest Protection, Taiwan Forestry Research Institute, Taipei, Taiwan for kindly supplying the strain of $A$. cinnamomea and Mr. D.P. Chamberlin for critically reading the manuscript. This work was supported in part by grants NRICM-94-DBCMR-08 and NRICM-96-DBCMR-08 to JJC, NRICM-97-DBCMR-09 to NKH, and NRICM-97-DHM5 to MKL from the National Research Institute of Chinese Medicine, Taiwan.

\section{References}

[1] Albano R, Mourio P. Presence of sulfated glycans in Ascidian tunic and in the body wall of a sea cucumber. Biochim Biophys Acta 1983;760:192-6.

[2] Albano R, Mourio P. Isolation, fractionation, and preliminary characterization of a novel class of sulfated glycans from the tunic of Styela plicata. J Biol Chem 1986;261:758-65.

[3] Mourio P, Perlin A. Highly acidic glycans from sea cucumbers. Isolation and fractionation of fucose-rich sulfated polysaccharides from the body wall of Ludwigothurea grisea. Eur J Biochem 1987;166:431-6.

[4] Pavio M, Albano R, Lawson A, Mourio P. Structural heterogeneity among unique sulfated L-galactans from different species of ascidians (tunicates). J Biol Chem 1989;264:9972-9.

[5] Pavio M, Albano R, Mourio P. L-Galactose in sulfated polysaccharides from tunicates. Carbohyd Res 1989;189:374-9.

[6] Cohen T, Gitay-Goren H, Sharon R, Shibuya M, Halaban R, Levi B, et al. VEGF121, a vascular endothelial growth factor (VEGF) isoform lacking heparin binding ability, requires cell-surface heparan sulfates for efficient binding to the VEGF receptors of human melanoma cells. J Biol Chem 1995;270:11322-6.

[7] Vlodavsky I, Miao H, Medalion B, Danagher P, Ron D. Involvement of heparan sulfate and related molecules in sequestration and growth promoting activity of fibroblast growth factor. Cancer Metast Rev 1996;15:177-86.
[8] Parish C, Freeman C, Brown K, Francis D, Cowden W. Identification of sulfated oligosaccharide-based inhibitors of tumor growth and metastasis using nove in vitro assays for angiogenesis and heparanase activity. Cancer Res 1999;59:3433-41.

[9] Hsu F, Chou C, Chang Y, Chang T, Lu M. Promotion of hyphal growth and underlying chemical changes in Antrodia cinnamomea by host factors from Cinnamomum cinnamomea. Int J Food Microbiol 2006;106:32-8.

[10] Tsai Z, Liaw S. The use and the effect of ganoderma. Taichung, Taiwan: San Yun Press; 1985. p. 116-117.

[11] Chen C, Yang S, Shen Y. New steroid acids from Antrodia cinnamomea, a fungal parasite of Cinnamomum micranthum. J Nat Prod 1995;58:1655-61.

[12] Cherng I, Chiang H. Three new triterpenoids from Antrodia cinnamomea. J Nat Prod 1995;58:365-71.

[13] Cherng I, Wu D, Chiang H. Triterpenoids from Antrodia cinnamomea. Phytochemistry 1996;41:263-7.

[14] Yang S, Shen Y, Chen C. Steroids and triterpenoids of Antrodia cinnamomea-a fungus parasitic on Cinnamomum micranthum. Phytochemistry 1996;41:138992.

[15] Hseu Y, Chang W, Hseu Y, Lee C, Yech Y, Chen P, et al. Protection of oxidative damage by aqueous extract from Antrodia camphorata mycelia in normal human erythrocytes. Life Sci 2002;71:469-82.

[16] Song T, Yen G. Antioxidant properties of Antrodia camphorata in submerged culture. J Agri Food Chem 2002;50:3322-7.

[17] Hsiao G, Shen M, Lin K, Lan M, Wu L, Chou D, et al. Antioxidative and hepatoprotective effects of Antrodia camphorata extract. J Agri Food Chem 2003;51:3302-8.

[18] Wang G, Tseng H, Chou C, Tsai T, Chen C, Lu M. The vasorelaxation of Antrodia camphorata mycelia: involvement of endothelial $\mathrm{Ca}(2+)-\mathrm{NO}-$ cGMP pathway. Life Sci 2003;73:2769-83.

[19] Shen Y, Chou C, Wang Y, Chen C, Chou Y, Lu M. Anti-inflammatory activity of the extracts from mycelia of Antrodia camphorata cultured with water-soluble fractions from five different Cinnamomum species. FEMS Microbiol Lett 2004;231:137-43.

[20] Lee I, Huang R, Chen C, Chen H, Hsu W, Lu M. Antrodia camphorata polysaccharides exhibit anti-hepatitis B virus effects. FEMS Microbiol Lett 2002;209:63-7.

[21] Shu C, Lung M. Effect of $\mathrm{pH}$ on the production and molecular weight distribution of exopolysaccharide by Antrodia camphorata in batch cultures. Process Biochem 2004;39:931-7.

[22] Ferrara N, Henzel W. Pituitary follicular cells secrete a novel heparin-binding growth factor specific for vascular endothelial cells. Biochem Biophys Res Co 1989;161:851-8.

[23] Giatromanolaki A, Koukourakis M, O’Byrne K, Fox S, Whitehouse R, Talbot D, et al. Prognostic value of angiogenesis in operable non-small cell lung cancer.J Pathol 1996;179:80-8.

[24] Giatromanolaki A, Sivridis E, Koukourakis M, Georgoulias V, Gatter K, Harris A Intratumoral angiogenesis: a new prognostic indicator for stage I endometrial adenocarcinomas? Oncol Res 1999;11:205-12.

[25] Koukourakis M, Giatromanolaki A, Fountzilas G, Sivridis E, Gatter K, Harris A Angiogenesis, thymidine phosphorylase, and resistance of squamous cell head and neck cancer to cytotoxic and radiation therapy. Clin Cancer Res 2000;6:3819.

[26] Ho J, Konerding M, Gaumann A, Groth M, Liu W. Fungal polysaccharopeptide inhibits tumor angiogenesis and tumor growth in mice. Life Sci 2004;75:134356.

[27] Huang N, Cheng J, Lai W, Lu M. Antrodia camphorata prevents rat pheochromocytoma cells from serum deprivation-induced apoptosis. FEMS Microbiol Lett 2005;244:213-9.

[28] Lu M, Cheng J, Lai W, Lin Y, Huang N. Adenosine as an active component of Antrodia cinnamomea that prevents rat PC12 cells from serum deprivationinduced apoptosis through the activation of Adenosine A2A receptors. Life Sci 2006;79:225-32. 
[29] Lu M, Cheng J, Lai W, Lin Y, Huang N. Fermented Antrodia cinnamomea extract prevents rat PC12 cells from serum deprivation-induced apoptosis: the role of the MAPK family. J Agri Food Chem 2008;56:865-74.

[30] Moskowitz S, Basu S, Bergold P. Chronic and cyclical neuronal loss in hippocampal slice cultures following transient inhibition of the type 1 isoform of superoxide dismutase. Brain Res 2001;913:207-19.

[31] Ratan R, Murphy T, Baraban J. Oxidative stress induces apoptosis in embryonic cortical neurons. J Neurochem 1994:62:376-9.

[32] Ferrari G, Yan C, Greene L, N-acetylcysteine. (D- and L-stereoisomers) prevents apoptotic death of neuronal cells. J Neurosci 1995;15:2857-66.

[33] Mosmann T. Rapid colorimetric assay for cellular growth and survival: application to proliferation and cytotoxicity assays. J Immunol Methods 1983;65: 55-63.

[34] Jones M, Wang H, Peskar B, Levin E, Itani R, Sarfeh I, et al. Inhibition of angiogenesis by nonsteroidal anti-inflammatory drugs: insight into mechan- isms and implications for cancer growth and ulcer healing. Nat Med 1999;5:1418-23.

[35] Saito H, Yamagata T, Suzuki S. Enzymatic methods for the determination of small quantities of isomeric chondroitin sulfates. J Biol Chem 1968;243:153642.

[36] Vieira R, Mulloy B, Mouriio P. Structure of a fucose-branched chondroitin sulfate from sea cucumber. J Biol Chem 1991;266:13530-6.

[37] Zierer M, Mourao P. A wide diversity of sulfated polysaccharides are synthesized by different species of marine sponges. Carbohyd Res 2000;328:209-16.

[38] Cui J, Chisti Y. Polysaccharopeptides of Coriolus versicolor: physiological activity, uses, and production. Biotechnol Adv 2003;21:109-22.

[39] Presta M, Oreste P, Zoppetti G, Belleri M, Tanghetti E, Leali D, et al. Antiangiogenic activity of semisynthetic biotechnological heparins. Low-molecularweight-sulfated Escherichia coli K5 polysaccharide derivatives as fibroblast growth factor antagonists. Arterioscl Throm Vas Biol 2005;25:71-6. 